\title{
New Inorganic Scintillation Materials Development for Medical Imaging
}

\author{
Paul Lecoq and Mikhail Korzhik
}

\begin{abstract}
As already advertised for several years, Lu-based compounds doped with trivalent Ce seem to be the most promising scintillators for a new generation of positron emission tomography scanners. Two crystals, namely LSO : Ce and LuAP:Ce, are under intensive study, but there is still an interest in searching for materials with a better combination of price/performance. In the study reported in this paper, we paid attention to the compounds containing rare earth and Ba, Hf. Another motivation was an increase of the effective charge of the host matrix and a decrease of the $\mathrm{Lu}$ fraction in compound. In this paper, we discuss spectroscopic properties of several new heavy compounds such as $\mathrm{Lu}_{2} \mathrm{Hf}_{2} \mathrm{O}_{7}, \mathrm{La}_{2} \mathrm{Hf}_{2} \mathrm{O}_{7}$ and $\mathrm{Ba}_{3} \mathrm{Lu}_{4} \mathrm{O}_{9}$ doped with $\mathrm{Ce}$.
\end{abstract}

Index Terms - Crystal, medical imaging, rare earth, scintillator.

\section{INTRODUCTION}

$\mathbf{T}$ HE DEVELOPMENT of new scintillators was boosted about ten years ago by a large coordinated effort around the Crystal Clear Collaboration at CERN [1] and the organization of the "SCINT" cycle of dedicated conferences. A large number of luminescent inorganic compounds have focused the interest on several new groups of crystalline scintillation materials. Ce-doped complex oxide compounds form a group of very attractive scintillation materials when crystallized in single crystalline phase. Among them, garnets $\mathrm{A}_{3} \mathrm{~B}_{5} \mathrm{O}_{12}(\mathrm{~A}=\mathrm{Lu}$, $\mathrm{Gd}, \mathrm{Y}, \mathrm{La} ; \mathrm{B}=\mathrm{Al}, \mathrm{Sc}$ ), perovskites $\mathrm{AAlO}_{3}$, oxyorthosilicates $\mathrm{A}_{2} \mathrm{SiO}_{5}$, borates, and phosphides of different structure [2]-[4] deserve particular attention. With the increase of the rare earth ion atomic number, the compound becomes heavy, giving rise to an efficient conversion of the ionizing radiation. Moreover, in the low-energy range of $\gamma$-quanta $\left(E_{\gamma} \leq 1 \mathrm{MeV}\right)$, the effective charge of the scintillation compound $\bar{Z}_{\text {eff }}$ plays a major role in detecting irradiation though photoeffect [5], which is proportional to $\left(Z_{\mathrm{eff}}\right)^{4}$. The use of $\mathrm{Lu}$, the heaviest rare earth element, has allowed the production of heavy compounds in each of the mentioned structural class. But the limit of density and effective charge increase is certainly not reached yet. This is why we proposed to study compounds in which the increase of the effective charge is also achieved by the choice of a heavy second cation in the matrix host [6]. We paid attention to the rare earth $\mathrm{Ba}$ and $\mathrm{Hf}$ compounds, which, being doped with $\mathrm{Ce}$, show luminescence in the blue-green region. Both the effective charge increase of the host matrix and the decrease or even replacement

Manuscript received October 31, 2001; revised April 9, 2002. This work was supported in part by the International Scientific and Technical Center, Moscow, under Project 2039.

P. Lecoq is with CERN, CH-1211, 23 Geneva, Switzerland (e-mail: Paul.Lecoq@cern.ch).

M. Korzhik is with the Institute for Nuclear Problems, 220050 Minsk, Belarus (e-mail: Mikhail.Korjik@cern.ch).

Digital Object Identifier 10.1109/TNS.2002.801487 of the relatively expensive Lu ion in the crystal motivated us for this research.

In this paper, we discuss the spectroscopic properties of several new heavy compounds, such as $\mathrm{La}_{2} \mathrm{Hf}_{2} \mathrm{O}_{7}$ and $\mathrm{Ba}_{3} \mathrm{Lu}_{4} \mathrm{O}_{9}$ doped with Ce. Another motivation of our study is to clarify the existence of the trivalent $\mathrm{Ce}$ interconfiguration $5 \mathrm{~d} \rightarrow 4 \mathrm{f}$ luminescence in the complex structure oxide compounds where the second heavy cation of the matrix host has an electronic shell $5 \mathrm{p}$. It is well known that room-temperature high light yield of $5 \mathrm{~d} \rightarrow 4 \mathrm{f}$ luminescence of $\mathrm{Ce}^{3+}$ is observed in oxides where the second cation is $\mathrm{B}^{3+}\left(1 \mathrm{~s}^{2}\right) ; \mathrm{Si}^{4+}, \mathrm{Al}^{3+}\left(2 \mathrm{p}^{6}\right)$; $\mathrm{Sc}^{3+}\left(3 \mathrm{p}^{6}\right)$ [2]-[4]. However, it was not observed in $\mathrm{Nb}^{5+}\left(4 \mathrm{p}^{6}\right)-$ or $\mathrm{Ta}^{5+}\left(5 \mathrm{p}^{6}\right)$-based compounds. On the other hand, our observation of the $\mathrm{Ce}^{3+}$ luminescence in the $\mathrm{Hf}^{4+}\left(5 p^{6}\right)$ - and $\mathrm{Ba}^{2+}\left(5 \mathrm{p}^{6}\right)$-based compounds shows that they are different from tantalates and niobates. We also continued our line of study of tungstate crystals and report the spectroscopy of Luand Y-based tungstate compounds. Finally, a systematic study of the intrinsic luminescence of undoped $\mathrm{LuAlO}_{3} \mathrm{LuAP}$ shows the high-light-yield potential of this crystal, only limited at present by not yet optimized production technology.

\section{Study OF New COMPOUNDS}

Several polycrystalline compounds, which are listed in Table I, have been investigated. Undoped and Ce-doped samples of the five listed materials have been obtained by solid phase synthesis from stochiometricaly mixed oxides at $1400{ }^{\circ} \mathrm{C}$ in air. One atomic percent of $\mathrm{Ce}$ dioxide has been blended to each compound, which have been annealed in a covered Pt crucible. Then they, excluding $\mathrm{La}_{2} \mathrm{Hf}_{2} \mathrm{O}_{7}$, have been annealed in two steps for $6 \mathrm{~h}$ each. The crystalline structure has been controlled by X-ray diffraction method after each step to control an appearance of appropriate phase. The fraction of the desired phase in the mixtures after the second step was 95, 70, 50,50 , and $30 \%$ respectively. The other fraction was composite of unreacted oxides.

In spite of a relatively high crystallization temperature, at least two compounds, $\mathrm{La}_{2} \mathrm{Hf}_{2} \mathrm{O}_{7}$ and $\mathrm{Ba}_{3} \mathrm{Lu}_{4} \mathrm{O}_{9}$, which exist in single crystalline form, may be competitive in density and effective charge to the well-known $\mathrm{Lu}_{2} \mathrm{SiO}_{5}: \mathrm{Ce}$ and $\mathrm{LuAlO}_{3}: \mathrm{Ce}$. Moreover, $\mathrm{La}_{2} \mathrm{Hf}_{2} \mathrm{O}_{7}$ does not contain the expensive lutetium, whereas its fraction in $\mathrm{Ba}_{3} \mathrm{Lu}_{4} \mathrm{O}_{9}$ is reasonably small.

In addition, two tungstate compounds, $\mathrm{Y}_{2} \mathrm{~W}_{3} \mathrm{O}_{12}$ and $\mathrm{Lu}_{2} \mathrm{~W}_{3} \mathrm{O}_{12}$, have been studied. They have a rather low density of 4.85 and $5.34 \mathrm{~g} / \mathrm{cm}^{3}$; however, their $Z_{\mathrm{eff}}$ is 65 and 69 , respectively. The Y-based compound has been smelted at $1200{ }^{\circ} \mathrm{C}$, and the Lu-based compound has been prepared according to the above-mentioned procedure. 
TABLE I

SOME Physical Properties of THE STUdied COMPOUNDS

\begin{tabular}{|c|c|c|c|c|}
\hline Compound & $\begin{array}{l}\text { Structural type } \\
\text { and space } \\
\text { group }\end{array}$ & $\begin{array}{l}\rho, \\
\mathrm{g} / \mathrm{cm}^{3}\end{array}$ & $\overline{Z_{\text {eff }}}$ & $\begin{array}{l}\text { Melt. } \\
\text { Point, } \\
{ }^{\circ} \mathrm{C}\end{array}$ \\
\hline $\mathrm{La}_{2} \mathrm{Hf}_{2} \mathrm{O}_{7}$ & $\begin{array}{l}\text { Pyrochlor } \\
\text { Ed3m }\end{array}$ & 7.84 & 64 & 2285 \\
\hline $\mathrm{Y}_{2} \mathrm{O}_{3}-\mathrm{HfO}_{2}$ & Fluorite Fm $3 \mathrm{~m}$ & 6.8 & 62 & 2400 \\
\hline $\mathrm{Lu}_{2} \mathrm{O}_{3}-\mathrm{HfO}_{2}$ & Fluorite Fm $3 \mathrm{~m}$ & 8.8 & 69 & 2510 \\
\hline $\mathrm{BaLa}_{2} \mathrm{O}_{4}$ & $\begin{array}{l}\text { Rhombic } \\
\text { Pnam }\end{array}$ & 6.34 & 54 & 1845 \\
\hline $\mathrm{Ba}_{3} \mathrm{Lu}_{4} \mathrm{O}_{9}$ & $\begin{array}{l}\text { Hexagonal } \\
\text { R3m }\end{array}$ & 8 & 65 & 2210 \\
\hline
\end{tabular}

All undoped Hf- and Ba-based compounds did not show any luminescence under $122-\mathrm{keV} \mathrm{X}$-ray $\left({ }^{57} \mathrm{Co}, 15 \mathrm{mCi}\right)$ or ultraviolet (UV) excitation of a xenon or hydrogen lamp at room temperature. The room-temperature emission and excitation spectra of three of four compounds doped with $\mathrm{Ce}$ are shown in Fig. 1(a)-(c). $\mathrm{La}_{2} \mathrm{Hf}_{2} \mathrm{O}_{7}$ : Ce shows an intensive luminescence band peaked near $465 \mathrm{~nm}$ and excitation maxima near 268, 310 , and $371 \mathrm{~nm} . \mathrm{Lu}_{2} \mathrm{O}_{3}-\mathrm{HfO}_{2}(1: 1)$ shows a luminescence band peaked at $480 \mathrm{~nm}$ and excitation maxima at 268,310, and $365 \mathrm{~nm}$. Doped $\mathrm{BaLa}_{2} \mathrm{O}_{4}$ did not show any luminescence at room temperature. On the contrary, $\mathrm{Ba}_{3} \mathrm{Lu}_{4} \mathrm{O}_{9}$ : Ce shows also intensive luminescence band peaked at $510 \mathrm{~nm}$ and excitation maxima at 315,369 , and, very weakly, at $260 \mathrm{~nm}$.

All samples show a weak additional green luminescence band with maximum at $525 \mathrm{~nm}$ due to the presence of some amount of unreacted $\mathrm{CeO}_{2}$. This luminescence has an excitation maximum at $375 \mathrm{~nm}$. The same luminescence and excitation have been observed for pure $4 \mathrm{~N}$ cerium dioxide in powdered form. We do not exclude that the long-wavelength excitation band in all spectra results from the superposition of the $\mathrm{Ce}^{3+}$ excitation luminescence in compounds with the one from unreacted cerium. The common feature of the excitation spectra is the presence of three bands, the position of which varies from compound to compound. The two lower wavelength excitation bands are most probably due to transitions to the $t$ and $e$ components of the $5 \mathrm{~d}$ level splitted by crystalline field [7]. However, we did not resolve their structure at room temperature. One can suppose that $\mathrm{Ce}^{3+}$ interconfiguration luminescence, which is characterized by relatively high Stokes shift, is detected. Nevertheless, observation of $\mathrm{Ce}^{3+}$ luminescence in the compounds demonstrates that radiating $\mathrm{Ce}^{3+}$ level is reasonably below the conductive zone bottom. Thus a weak delocalization of the $\mathrm{Ce}^{3+}$ ion excitation through the conductive zone [8] occurs. Some tantalates [9] possess intrinsic scintillations. However, room-temperature $\mathrm{Ce}^{3+}$ luminescence has never been observed in them. Obtained samples shown low-light-yield luminescence under ${ }^{57} \mathrm{Co}(122 \mathrm{keV})$ irradiation. To clarify the scintillation properties of these compounds, another synthesis at temperatures close to the melting point is required.

Our study of tungstate compounds $\mathrm{Y}_{2} \mathrm{~W}_{3} \mathrm{O}_{12}$ and $\mathrm{Lu}_{2} \mathrm{~W}_{3} \mathrm{O}_{12}$ shows wide intensive luminescence bands in the green region under UV excitation. Luminescence and excitation spectra of undoped compounds are shown in Fig. 2. Doping with Ce does
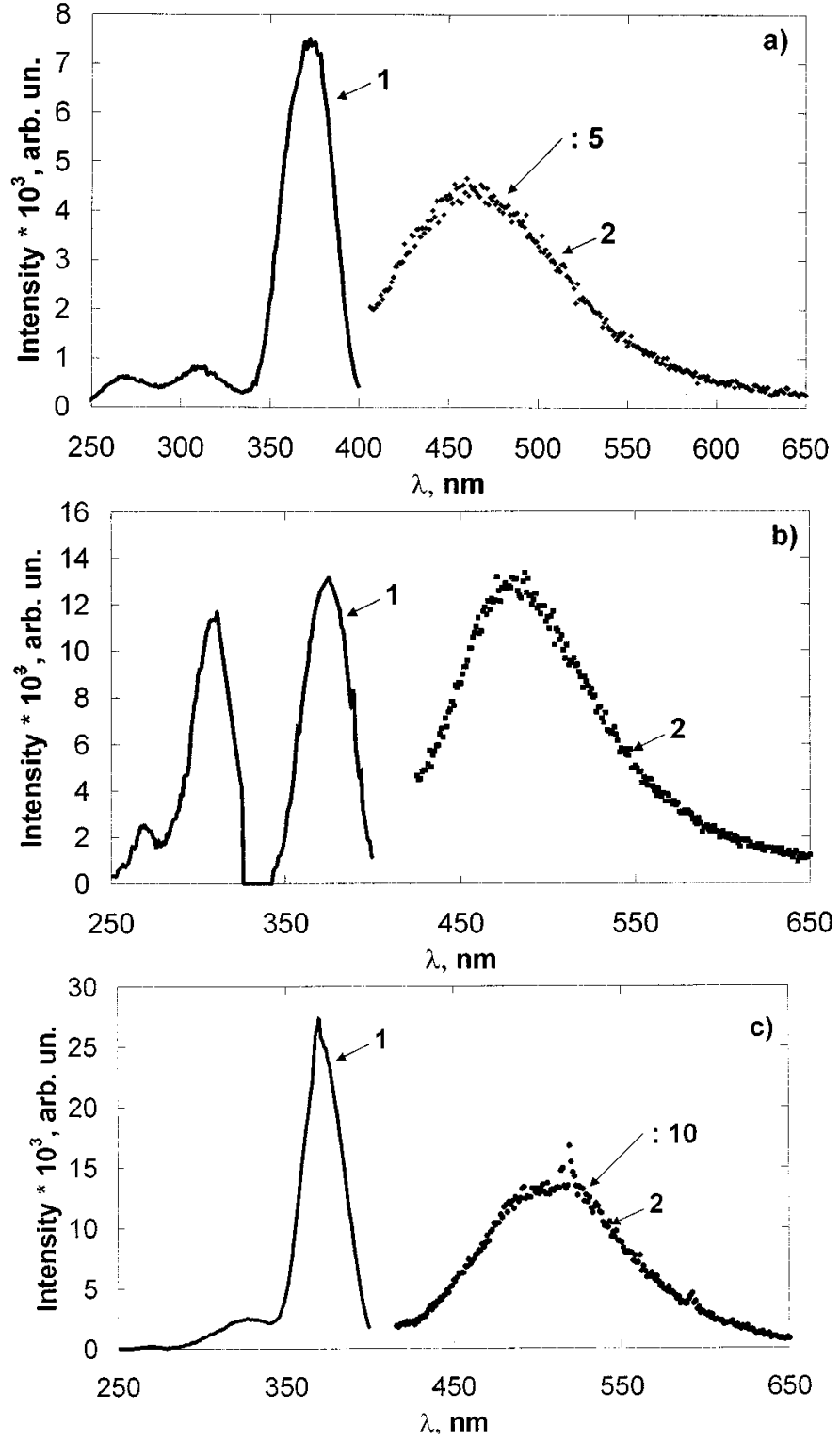

Fig. 1. Room-temperature luminescence (1) excitation and (2) spectra of (a) $\mathrm{La}_{2} \mathrm{Hf}_{2} \mathrm{O}_{7}: \mathrm{Ce}$, (b) $\mathrm{Lu}_{2} \mathrm{O}_{3}-\mathrm{HfO}_{2}: \mathrm{Ce}$, and (c) $\mathrm{Ba}_{3} \mathrm{Lu}_{4} \mathrm{O}_{9}:$ Ce. Luminescence band peak intensities (a), (c) decreased five and ten times, respectively.

not change the luminescence properties of these compounds. It indicates that $\mathrm{Ce}^{3+}$ 's lowest crystalline field split component of $5 \mathrm{~d}$ level is in a conducting zone. Thus fast excitation delocalization occurs and $\mathrm{Ce}^{3+}$ luminescence is not observed.

As for many tungstates, their spectroscopic properties are mainly caused by optical transitions in oxyanionic tungstate complexes $\mathrm{WO}_{4}^{2-}$. Both compounds' scintillation yield under $\gamma$-ray excitation is about $200 \mathrm{ph} / \mathrm{MeV}$ and similar to the yield of lead tungstate crystals at room temperature.

\section{Status of LuAP : Ce Scintillator DeVelopment}

To study the scintillation mechanism in LuAP crystals, undoped $\mathrm{LuAP}$ has been grown from $5 \mathrm{~N}$ raw material by Czochralski method. The ingot had a diameter of $18 \mathrm{~mm}$ and a length of $40 \mathrm{~mm}$. Several doped crystals with $\mathrm{Ce}^{3+}$ concentration of about 0.5 at.\% in the melt have also been grown by Czochralski method. 


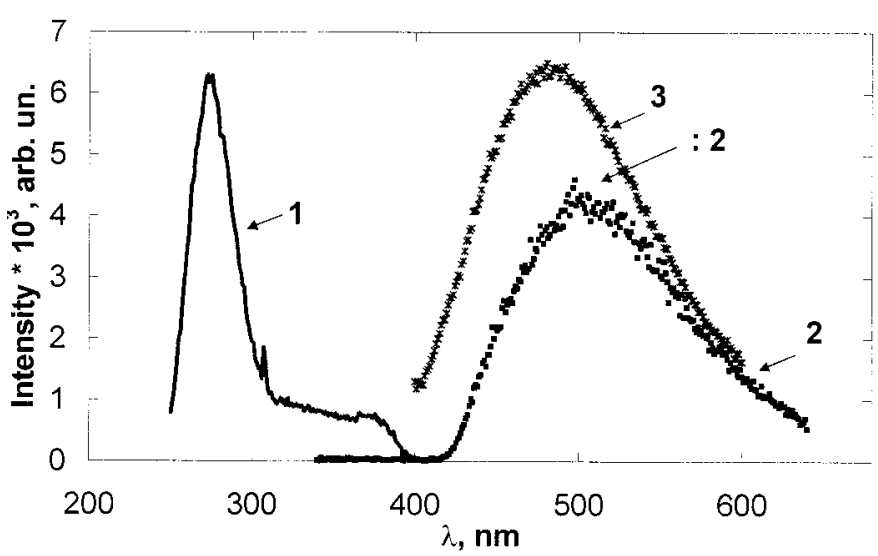

Fig. 2. Luminescence (1) excitation spectrum of $\mathrm{Y}_{2} \mathrm{~W}_{3} \mathrm{O}_{12}$ and (2) spectra for 300-nm excitation of $\mathrm{Y}_{2} \mathrm{~W}_{3} \mathrm{O}_{12}$ and (3) $\mathrm{Lu}_{2} \mathrm{~W}_{3} \mathrm{O}_{12}$ taken at room temperature. Peak intensity of $\mathrm{Y}_{2} \mathrm{~W}_{3} \mathrm{O}_{12}$ is increased two times.

It is the first time that undoped LuAP crystal has shown an intensive intrinsic luminescence with maximum at $318 \mathrm{~nm}$ under X-rays and UV excitation at room temperature. Details of the intrinsic luminescence properties are the subject of another paper. Here we draw attention to the fact that the observation of the appropriate intrinsic luminescence is a very good signal that high-light-yield scintillation can be achieved in this crystal when it is Ce-doped [10]. Table II shows the maxima of the intrinsic luminescence in several $\mathrm{Y}$ and $\mathrm{Lu}$ crystalline compounds. One can see that some of them have two characteristic intrinsic luminescence bands. We did not observe a shorter wavelength intrinsic luminescence in pure LuAP similar to Kuznetsov [11]-[13], who detected $\mathrm{YAlO}_{3}$ YAP intrinsic luminescence peaked at $223 \mathrm{~nm}$ for an excitation near $156 \mathrm{~nm}$. On the other hand, the LuAP excitation spectrum shows that both luminescence bands recognized in Y-based garnet and perovskite should also exist in LuAP. Only one is seen because spectrum cutoff in our undoped crystal is near $230 \mathrm{~nm}$ and short wavelength luminescence band is strongly absorbed.

One can thus state that the intrinsic luminescence bands with maxima near 250 and $300 \mathrm{~nm}$ are common features of both oxyaluminum and oxysilicium complex structure crystalline $\mathrm{Y}$ or Lu-based compounds. It would be interesting to make such a study in $\mathrm{Lu}_{2} \mathrm{SiO}_{5}$ crystals, for which published data so far are only related to Ce-doped crystals.

There are several interpretations of the intrinsic luminescence bands origin. The spectroscopic data are easily corrupted by technological factors, and no clear correlation between electron paramagnetic resonance (EPR) and intrinsic luminescence properties is observed. Schirmer [14] detected two types of $\mathrm{O}^{-}$ hole centers in undoped YAP crystal. It was suggested that $\mathrm{O}^{-}$ centers appear due to the localization of the hole near a vacancy in the heaviest cation site. On the other hand, it is not excluded that holes could be self-trapped or rather stabilized by $\mathrm{O}^{2-}$ ions in distorted sites. Three $\mathrm{O}^{-}$-type centers were detected by EPR at liquid He temperature in undoped $\mathrm{Y}_{3} \mathrm{~A}_{l 5} \mathrm{O}_{12}$ YAG [15]. The localization of holes near vacancies of the heaviest ion somehow contradicts crystal growth peculiarities in the system $\mathrm{Y}_{2} \mathrm{O}_{3}-\mathrm{Al}_{2} \mathrm{O}_{3}$. For the perovskite phase, the dominating leakage from the melt is observed to be of the aluminum oxide.
TABLE II

MAXIMA OF INTRINSIC LUMINESCENCE BANDS IN SOME COMPLEX OXide CRystals at RoOM Temperature

\begin{tabular}{l|l|l|l}
\hline Crystal & $\begin{array}{l}\text { Short } \lambda \text { band, } \\
\text { nm }\end{array}$ & $\begin{array}{l}\text { Long } \lambda \text { band, } \\
\text { nm }\end{array}$ & Ref. \\
\hline $\mathrm{Y}_{3} \mathrm{Al}_{5} \mathrm{O}_{12}$ & 255 & 297 & 15,11 \\
\hline $\mathrm{YAlO}_{3}$ & 223 & 298 & $10,11,18$ \\
\hline $\mathrm{Y}_{2} \mathrm{SiO}_{5}$ & & 301 & 16 \\
\hline $\mathrm{Lu}_{3} \mathrm{Al}_{5} \mathrm{O}_{12}$ & & 320 & 17 \\
\hline $\mathrm{LuAlO}_{3}$ & & 318 & Current \\
\hline
\end{tabular}

Thus vacancies in the $\mathrm{Al}$ sites will dominate. The same is true for the growth of yttrium aluminum garnet. This situation is even more dramatic in LuAP, where a very small deficiency of Lu in the melt provokes the creation of the garnet phase. The interpretation of the observed intrinsic luminescence bands by the radiative recombination of self-trapped excitons (STEs) (short wavelength) and self-trapped holes (STHs) [18] looks more reasonable. Examination of complex oxide compound structures clearly shows that $\mathrm{Al}$ or $\mathrm{Si}$ oxygen polyhedra are distorted in such a way that hole and exciton self-trapping in regular oxygen sites becomes possible. The observation of only two intrinsic luminescence bands in all the mentioned crystals obtained by different methods supports this hypothesis. In fact, self-trapped holes either recombine radiatively with thermalized electrons or create excitons with further radiative recombination.

The 318-nm intrinsic luminescence shows several maxima in excitation, which are peaked at $84,112,125,154$, and $162 \mathrm{~nm}$ at room temperature. An important conclusion from the excitation spectra is the effective excitation of the intrinsic luminescence not only at the fundamental absorption edge $(154,162 \mathrm{~nm})$ but also through excitation of electrons from Lu $4 f$ filled shell (84 nm) [19] to the conduction band. When LuAP is doped with $\mathrm{Ce}$, we only observe the interconfiguration luminescence of $\mathrm{Ce}^{3+}$ ions above liquid He temperature. However, both edge excitation bands observed in undoped crystals are also detected in excitation of trivalent Ce luminescence. It indicates that STE and STH effectively sensitize luminescence of $\mathrm{Ce}^{3+}$ ions.

Through comparison of the integrals under the X-ray luminescence spectra curves, the light yield of undoped LuAP is estimated to be $11000-13000 \mathrm{Ph} / \mathrm{MeV}$, compared to $9000 \mathrm{Ph} / \mathrm{MeV}$ for YAP [20]. For the moment, typical light yield of mass-produced YAP:Ce crystals is $14500 \mathrm{ph} / \mathrm{MeV}$ [21]. However, light yield obtained from LuAP:Ce samples is not more than $9000 \mathrm{ph} / \mathrm{MeV}$ and is strongly dependent on technological factors. The $\mathrm{Ce}^{3+}$ ion is excited through both charge transfer [22] and energy transfer from STE and STH. Comparison of the light yields of doped and undoped crystals shows that sensitizing of the $\mathrm{Ce}^{3+}$ luminescence substantially contributes to the total yield of scintillation in doped crystals. A brighter STE-STH luminescence causes a larger yield of $\mathrm{Ce}^{3+}$ scintillation. The study described in this paper gives evidence that the light yield of Lu perovskite can potentially be larger than that of YAP. Further improvement is just a matter of technology progress. 


\section{CONCLUSION}

The compounds based on $5 \mathrm{p}^{6}$ outer shell $\mathrm{Hf}^{4+}$ and $\mathrm{Ba}^{2+}$, associated to $\mathrm{Lu}, \mathrm{La}$, or $\mathrm{Y}$, have shown an intensive luminescence in the blue-green region under UV excitation.

The study of the self-trapped excitonic emission in undoped LuAP crystals shows a potential for even greater light yield than what has been obtained so far.

\section{ACKNOWLEDGMENT}

The authors are grateful to A. Mikhlin, Institute of Rare Elements, Moscow, Russia, and G. Savtchuk, Institute for Solid State Physics, Minsk, Belarus, for preparation and X-ray diffraction analysis of the samples. They are also very thankful to P. Dorenbos and A. Borisevich from the Crystal Clear Collaboration for measurements of the samples' scintillation properties.

\section{REFERENCES}

[1] "Study of new fast and radiation hard scintillators for calorimetry at LHC," Crystal Clear Collaboration, RD 18, CERN/DRDC/P27/91-15.

[2] C. W. E. Eijk, "Development of inorganic scintillators," Nucl. Instrum. Methods, vol. A392, pp. 285-290, 1997.

[3] M. J. Weber, "Cerium activated crystal and glass scintillators," in Proc. Crystal 2000 Int. Workshop, F. de Notaristefani, P. Lecoq, and M. Scneegans, Eds, France: Editions Frontieres, 1993, pp. 99-104.

[4] W. P. Trower, M. V. Korzhik, and A. A. Fedorov et al., Cerium-Doped Lutetium-Based Single Crystal Scintillators. Inorganic Scintillators and their Applications, P. Dorenbos and C. W. E. Eijk, Eds. Delft, the Netherlands: Delft Univ. Press, 1995, pp. 241-245.

[5] "Scintillation detectors," Crismatec Catalog, 1992.

[6] M. Korzhik and P. Lecoq, "Search of new scintillation materials for nuclear medicine application," IEEE Trans. Nucl. Sci., vol. 48, pp. 628-632, Aug. 2001.
[7] P. Dorenbos, "The $5 \mathrm{~d}$ level positions of the trivalent lanthanides in inorganic compounds," J. Lumin., vol. 91, pp. 155-176, 2000.

[8] W. M. Yen, "Photoconductivity and delocalization in rare earth activated insulators," J. Lumin., vol. 83-84, pp. 399-404, 1999.

[9] L. I. Kazakova, A. B. Dubovski, G. V. Semenkovich, and O. A. Ivanova, "Luminescence of $\mathrm{YTaO}_{4}$ single crystals," Rad. Meas., vol. 24, pp. 359-360, 1995

[10] M. V. Korzhik and W. P. Trower, "Origin of scintillation in cerium doped oxide crystals," Appl. Phys. Lett., vol. 66, pp. 2327-2328, 1995.

[11] A. I. Kuznetsov, B. R. Namosov, and V. V. Murk, "Relaxed electronic states in $\mathrm{Al}_{2} \mathrm{O}_{3}, \mathrm{Y}_{3} \mathrm{Al}_{5} \mathrm{O}_{12}, \mathrm{YAlO}_{3}$," Sov. J. Phys. Solid State, vol. 27, pp. 3030-3035, 1985.

[12] A. I. Kuznetsov, V. N. Abramov, B. R. Namosov, and B. R. Uibo, "Recombination luminescence of $\mathrm{Y}_{3} \mathrm{Al}_{5} \mathrm{O}_{12}, \mathrm{YAlO}_{3}$ crystals" (in Russian), in Proc. Phys. Inst. Estonian Acad. Sci., vol. 53, pp. 83-87.

[13] A. I. Kuznetsov, V. N. Abramov, V. V. Murk, and B. R. Namosov, "States of the self-trapped excitons in complex oxides," S. J. Phys. Solid State, vol. 33, pp. 2000-2004, 1991.

[14] O. F. Schirmer, K. W. Blazey, and W. Berlinger, "ESP and optical absorption of bond-small polarons in $\mathrm{YAlO}_{3}$," Phys. Rev., vol. B11, pp. 4201-4211, 1975.

[15] W. Hyes, M. Jamaga, D. J. Robbins, and B. Cockayne, "Optical detection of EPR and recombination centers in YAG," J. Phys., vol. C13, pp. L1085-L1087, 1980.

[16] R. L. Wood and W. Hayes, "A study of recombination centers in $\mathrm{YAlO}_{3}$, $\mathrm{EuAlO}_{3}, \mathrm{LaAlO}_{3}$, and $\mathrm{Y}_{2} \mathrm{O}_{3}$ using ODMR," Rad. Eff., vol. 72, pp. 195-199, 1983.

[17] J. Andriessen, P. Dorenbos, and C. W. E. van Eijk, "Ce ${ }^{3+}$ doped scintillation materials," in Scintillators and Phosphor Materials, M. J. Weber, P. Lecoq, R. C. Ruchti, C. Woody, W. M. Yen, and R.-Y. Zhu, Eds. Pittsburgh, PA: MRS, 1994, pp. 355-359.

[18] V. Murk, A. Kuznetsov, B. Namozov, and K. Ismailov, "Relaxation of electronic excitiations in YAG and YAP crystals," Nucl. Instrum. Methods, vol. B91, pp. 327-331, 1994.

[19] C. Dujardin, C. Pedrini, J. C. Gacon, A. G. Petrosyan, A. N. Belski, and A. N. Vasiliev, "Luminescence properties and scintillation mechanisms of cerium- and praseodymium-doped luthetium ortoaluminate," J. Phys. Condens. Matter, vol. 9, pp. 5229-5245, 1997.

[20] P. Dorenbos, private communication.

[21] V. G. Baryshevsky, M. V. Korzhik, and V. I. Moroz et al., "Fast scintillating crystals for the detectors of ionizing radiation," Nucl. Instrum. Methods, vol. B58, pp. 291-294, 1991.

[22] V. V. Averkiev and J. A. Valbis, Luminescence Crystals and Convertors of Ionizing Radiation (in Russian). Novosibirsk: Nauka, 1985, p. 30. 